\title{
Endobronchial one-way valves for treatment of persistent air leaks: a systematic review
}

\author{
Mei Ding ${ }^{1}$ Ya-dong Gao ${ }^{*}$, Xian-Tao Zeng ${ }^{2}$, Yi Guo $^{2}$ and Jiong Yang ${ }^{1}$
}

\begin{abstract}
Persistent air leak (PAL) is associated with significant morbidity and mortality, prolonged hospitalization and increased health-care costs. It can arise from a number of conditions, including pneumothorax, necrotizing infection, trauma, malignancies, procedural interventions and complications after thoracic surgery. Numerous therapeutic options, including noninvasive and invasive techniques, are available to treat PALs. Recently, endobronchial one-way valves have been used to treat PAL. We conducted a systematic review based on studies retrieved from PubMed, EMbase and Cochrane library. We also did a hand-search in the bibliographies of relevant articles for additional studies. 34 case reports and 10 case series comprising 208 patients were included in our review. Only 4 patients were children, most of the patients were males. The most common underlying disease was COPD, emphysema and cancer. The most remarkable cause was pneumothorax. The upper lobes were the most frequent locations of air leaks. Complete resolution was gained within less than $24 \mathrm{~h}$ in majority of patients. Complications were migration or expectoration of valves, moderate oxygen desaturation and infection of related lung. No death related to endobronchial one-way valves implantation has been found. The use of endobronchial one-way valve adds to the armamentarium for non-invasive treatments of challenging PAL, especially those with difficulties of anesthesia, poor condition and high morbidity. Nevertheless, prospective randomized control trials with large sample should be needed to further evaluate the effects and safety of endobronchial one-way valve implantation in the treatment of PAL.
\end{abstract}

Keywords: Persistent air leak, Bronchopleural fistulas, Alveolar-pleural fistulas, Endobronchial valve, Bronchoscopic intervention

\section{Background}

Pulmonary air leak is a common clinical problem which can be resulted from both bronchopleural fistulas (BPFs) and alveolar-pleural fistulas (APFs). BPFs are abnormal communications between the bronchial tree and the pleural space, while APFs are pathologic communications between the alveoli and pleural space [1]. Persistent air leak (PAL) is defined as those lasting more than 5 to 7 days postoperatively, without forced expiration or expulsion maneuvers $[2,3]$. The presence of PAL is associated with significant morbidity and mortality, prolonged hospitalization and increased health-care costs [4].

\footnotetext{
* Correspondence: gaoyadong@whu.edu.cn

'Department of Respiratory Medicine, Zhongnan Hospital of Wuhan University, Donghu Road 169, Wuhan 430071, People's Republic of China Full list of author information is available at the end of the article
}

Air leak, both BPF and APF, can arise from a number of conditions, including, but not limited to, pneumothorax, necrotizing infection, trauma, malignancies, procedural interventions (biopsy, CPR, radiofrequency ablation of lung tumors, etc) and complications after thoracic surgery [5-7]. Primary spontaneous pneumothorax rarely results in PAL; it is substantially more frequent $(20 \%)$ in the setting of underlying COPD [8]. Incidence of iatrogenic pneumothorax is reported at $1.36 \%$ in hospitalized patients due to invasive procedures or positive pressure ventilation [9]. More commonly, lung resections carry significant risks of PALs, with an incidence ranging from $8 \%$ after a sublobar resection to $45 \%$ after lung volume reduction surgery (LVRS). The incidence of postoperative air leak ranges from $28 \%$ to $60 \%$ immediately after surgery, $26 \%$ to $48 \%$ on postoperative day $1,22 \%$ to $24 \%$ on 
day 2, and $8 \%$ on day 4 [10-12]. The National Emphysema Treatment Trial suggests that postoperative air leak occur in $90 \%$ of patients undergoing bilateral LVRS procedures [13].

Numerous therapeutic options, including noninvasive and invasive techniques, are available to treat PALs. Noninvasive approaches rely on prolonged chest tube drainage either on water seal or Heimlich valve system or coupled with tailored ventilator strategies to establish acceptable ventilation while reducing the flow through the alveolar- or bronchopleural fistula. Invasive therapies include pleurodesis either surgical or at bedside through the indwelling chest tube, by instillation of talc slurry or doxycycline, mechanical pleurodesis by pleural abrasion, application of fibrin sealant, bronchial stump stapling, muscle flap construction, omental flap coverage, or pericardial fat pad flap to the bronchial stump, and surgical lobectomy $[5,14]$.

Recently, endobronchial one-way valves, initially designed for bronchoscopic lung volume reduction (BLVR) in emphysema, have been used to treat PAL. The objective of this article was to summarize current clinical evidence of the management of PAL with endobronchial one-way valves to define the role of this bronchoscopic intervention.

\section{Methods}

\section{Literature search strategy}

A search was conducted on PubMed, EMbase and Cochrane library for original studies published from 2005 to April 2017 on endobronchial one-way valves placement for treating PAL, using the keywords as "valve" AND "air leak" OR "bronchopleural fistula" OR "alveolar-pleural fistula". We also did a hand-search in the bibliographies of relevant articles for additional studies.

\section{Selection criteria}

Studies reporting data on endobronchial one-way valves in the treatment of PAL were included in this review.
Abstracts, animal studies and studies published in languages other than English and German were excluded from this review.

\section{Definitions}

Persistent air leak was defined as the presence of an air leak lasting more than 5 days with postsurgical or medical etiology. In studies where a different definition was used, we adopted the definition specified by the authors of the selected papers.

\section{Results}

\section{Description of included studies}

One hundred and seventy- three full-length articles were identified by our literature search. After being appraised, 129 were excluded due to the following reasons: articles that referred to the use of endobronchial one-way valves in COPD $(n=11)$, articles that referred to the valves other than endobronchial one-way valves $(n=85)$, animal studies $(n=3)$, reviews $(n=8)$, articles written in the excluded languages $(n=2)$ and duplicated cases $(\mathrm{n}=11)$, meeting abstract $(n=9)$. The search strategy was showed in Fig. 1.

\section{Case reports of PAL treated with endobronchial one-way valves}

Characteristics of included case reports are shown in Table 1, data for 52 patients from 34 case reports are available [15-48]. Age of patients ranged from 18 to 93 years with median age at 57 years. Most of the patients were males $(28 / 51,54.9 \%)$. The most common underlying diseases in patients were lung infection $(11 / 52,21.2 \%)$, cancer $(14 / 52,26.9 \%)$ and lung related diseases (26/52, 50\%) which included bronchiectasis, COPD, cystic fibrosis, bulla and lymphangioleiomyomatosis.

Clinical features of air leak: the most remarkable cause was pneumothorax (tension pneumothorax comprised) (35/52, 67.3\%). Postoperative air leak and empyema were

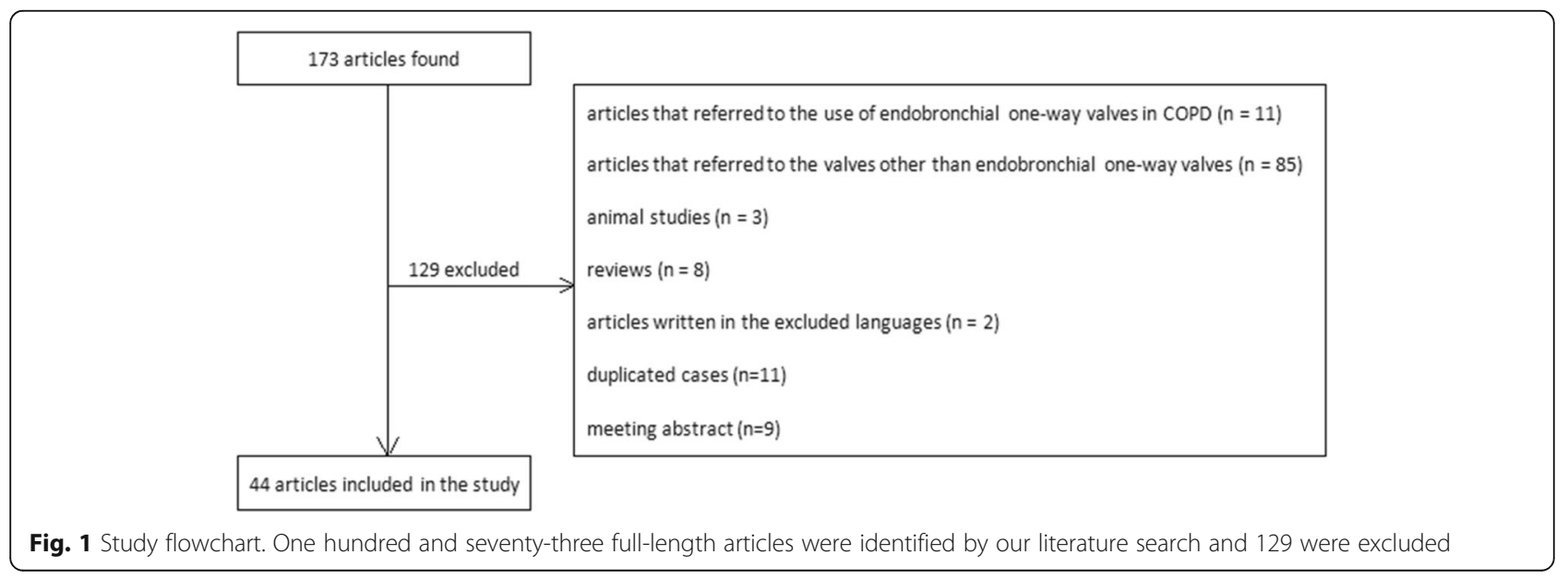


Table 1 Characteristics of patients and endobronchial one-way valve deployment in case reports included

\begin{tabular}{|c|c|c|}
\hline & $\mathrm{n} / \mathrm{N}$ & Percentag \\
\hline \multicolumn{3}{|l|}{ Demographics } \\
\hline Age (years), median (range) & $57(18-93)$ & \\
\hline Male sex & $28 / 51^{\mathrm{a}}$ & $54.9 \%$ \\
\hline Female sex & $23 / 51^{\mathrm{a}}$ & $45.1 \%$ \\
\hline \multicolumn{3}{|l|}{ Underlying diseases } \\
\hline Lung infection & $11 / 52$ & $21.2 \%$ \\
\hline Infections of other sites & $1 / 52$ & $2 \%$ \\
\hline Lung related diseases & $26 / 52$ & $50 \%$ \\
\hline Chest trauma & $1 / 52$ & $2 \%$ \\
\hline Cancer & $14 / 52$ & $26.9 \%$ \\
\hline Systematic diseases & $3 / 52$ & $5.8 \%$ \\
\hline \multicolumn{3}{|l|}{ Causes of air leak } \\
\hline Pneumothorax & $23 / 52$ & $44.2 \%$ \\
\hline Tension pneumothorax & $6 / 52$ & $11.5 \%$ \\
\hline latrogenic pneumothorax & $6 / 52$ & $11.5 \%$ \\
\hline Broncho-cutaneous fistula & $1 / 52$ & $2 \%$ \\
\hline Bronchopleural fistula & $6 / 52$ & $11.5 \%$ \\
\hline $\begin{array}{l}\text { Alveolar-pleural and trans-diaphragmatic } \\
\text { fistula }\end{array}$ & $1 / 52$ & $2 \%$ \\
\hline Empyema & $9 / 52$ & $17.3 \%$ \\
\hline Postoperative air leak & $12 / 52$ & $23.1 \%$ \\
\hline $\begin{array}{l}\text { Duration of air leak before endobronchial one- } \\
\text { way valve deployment (days),median (range) }\end{array}$ & $15,(3-2520)$ & \\
\hline \multicolumn{3}{|l|}{ Location of air leak } \\
\hline Right upper & $17 / 52$ & $32.7 \%$ \\
\hline Right middle & $6 / 52$ & $11.5 \%$ \\
\hline Right lower & $6 / 52$ & $11.5 \%$ \\
\hline Left upper & $15 / 52$ & $28.8 \%$ \\
\hline Left lower & $8 / 52$ & $15.4 \%$ \\
\hline Right main bronchus & $1 / 52$ & $2 \%$ \\
\hline Left main bronchus & $1 / 52$ & $2 \%$ \\
\hline Lingual & $5 / 52$ & $9.6 \%$ \\
\hline Bronchus intermedius & $1 / 52$ & $2 \%$ \\
\hline \multicolumn{3}{|l|}{ Type of endobronchial one-way valve used } \\
\hline Emphasys $^{\oplus}$ & $32 / 122$ & $26.2 \%$ \\
\hline Spiration ${ }^{\circledast} \mid \mathrm{BV}$ valves & $59 / 122$ & $48.4 \%$ \\
\hline Zephyr ${ }^{\circledast}$ & $31 / 122$ & $25.4 \%$ \\
\hline $\begin{array}{l}\text { Number of endobronchial one-way valves } \\
\text { (per patient),median (range) }\end{array}$ & $2,(1-8)$ & \\
\hline \multicolumn{3}{|l|}{$\begin{array}{l}\text { Duration of air leak after endobronchial } \\
\text { one-way valve deployment }\end{array}$} \\
\hline$<1$ day & $31 / 50^{b}$ & $62 \%$ \\
\hline 1 day $\leqq 2$ days & $6 / 50^{b}$ & $12 \%$ \\
\hline$>2$ days & $13 / 50^{\mathrm{b}}$ & $26 \%$ \\
\hline
\end{tabular}

Table 1 Characteristics of patients and endobronchial one-way valve deployment in case reports included (Continued)

\begin{tabular}{|c|c|c|}
\hline & $\mathrm{n} / \mathrm{N}$ & Percentage \\
\hline \multicolumn{3}{|l|}{ Outcomes } \\
\hline Removal of endobronchial one-way valve & $20 / 50^{c}$ & $40 \%$ \\
\hline Migration of endobronchial one-way valve & $1 / 50^{c}$ & $2 \%$ \\
\hline $\begin{array}{l}\text { Expectoration of endobronchial one-way } \\
\text { valve }\end{array}$ & $1 / 50^{c}$ & $2 \%$ \\
\hline Recurrence of air leak & $3 / 50^{c}$ & $6 \%$ \\
\hline $\begin{array}{l}\text { Death not related to deployment } \\
\text { of endobronchial one-way valve }\end{array}$ & $3 / 50^{c}$ & $6 \%$ \\
\hline
\end{tabular}

${ }^{a}$ sex of patient in one case report not given

bduration of initial air leak not given in 2 case reports

$c_{1}$ patient lost to follow-up and 1 patient without plan to valve removal

following significant causes of air leak with percentage at $23.1 \%$ and $17.3 \%$ respectively. The median duration of air leak before EBV deployment was 15 days. Air leak was most frequently located in upper lobes as $17 / 52$, $32.7 \%$ for right upper lobe and 15/52, $28.8 \%$ for left upper lobe. It was least located in main bronchi $(2 / 52$, $4 \%)$ and bronchus intermedius (1/52, $2 \%)$. The rest lobes shared an average location of air leak.

Information of endobronchial one-way valves: the median number of valves deployed in patients was 2 . Three commercial types of valves were used: Emphasys ${ }^{\circ}$ (32/ 122, 26.2\%), Spiration ${ }^{\circ}$ IBV valves $(59 / 122,48.4 \%)$ and Zephyr $^{\circ}$ valves (31/122, 25.4\%).

Outcome of endobronchial one-way valves deployment: optimal decrease of air leak was gained posterior valve deployment within less than $24 \mathrm{~h}$ in majority of patients $(31 / 50,62 \%)$. Valves were removed after cessation of air leak in 20/50 patients (40\%). One case of valve migration and another case of valve expectoration were described. Recurrence of air leak was reported in 3 patients. Three patients died after valve deployment but not related to the procedure. None of complication like infection was noted.

\section{Case series of PAL treated with endobronchial one-way valves}

Characteristics of included case series are shown in Table 2 and Table 3, data for 156 patients from 10 case series were identified in which half were prospective studies [14, 49-57]. Four children patients were reported while the rest were adults. Most of the patients were males (96/143, 67.1\%). The most common underlying disease was COPD, emphysema and cancer. The largest amount of endobronchial one-way valves were deployed in the upper lobes with $28.4 \%(75 / 264)$ of overall at right upper lobe and $26.5 \%(70 / 264)$ at left upper lobe. Complete resolution was obviously noted in all case series with rate ranging from $47.5 \%$ to $100 \%$. Ninety 


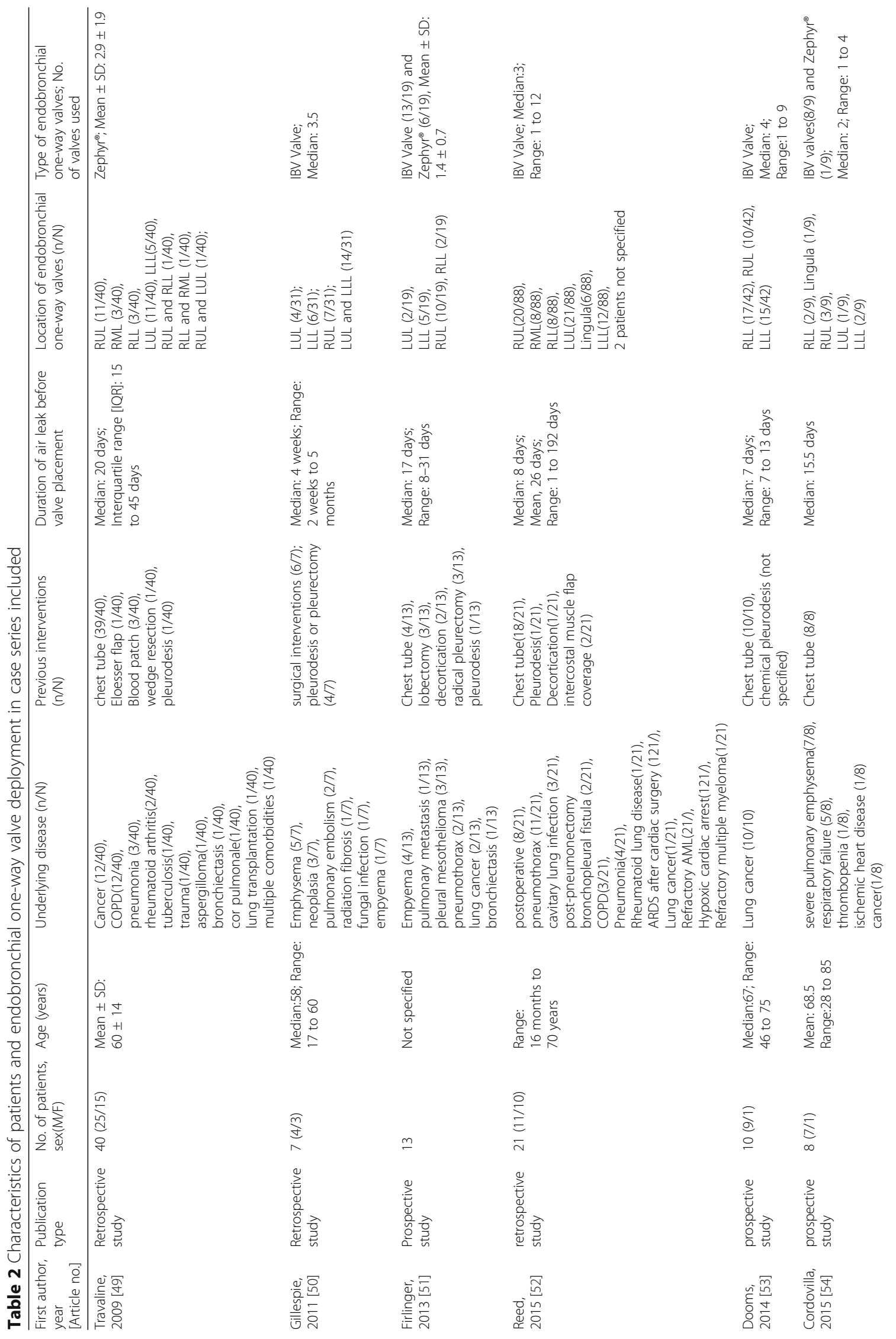




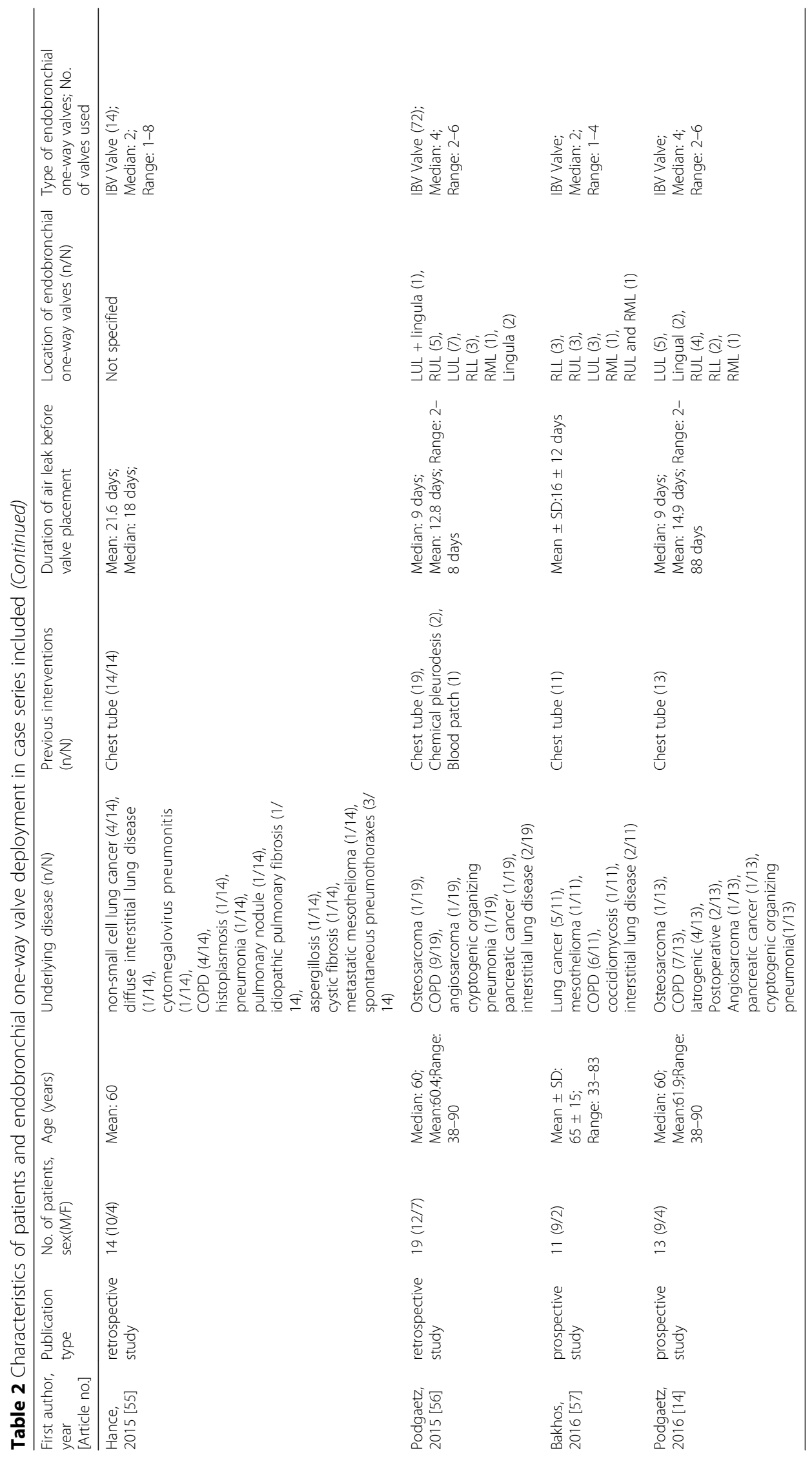




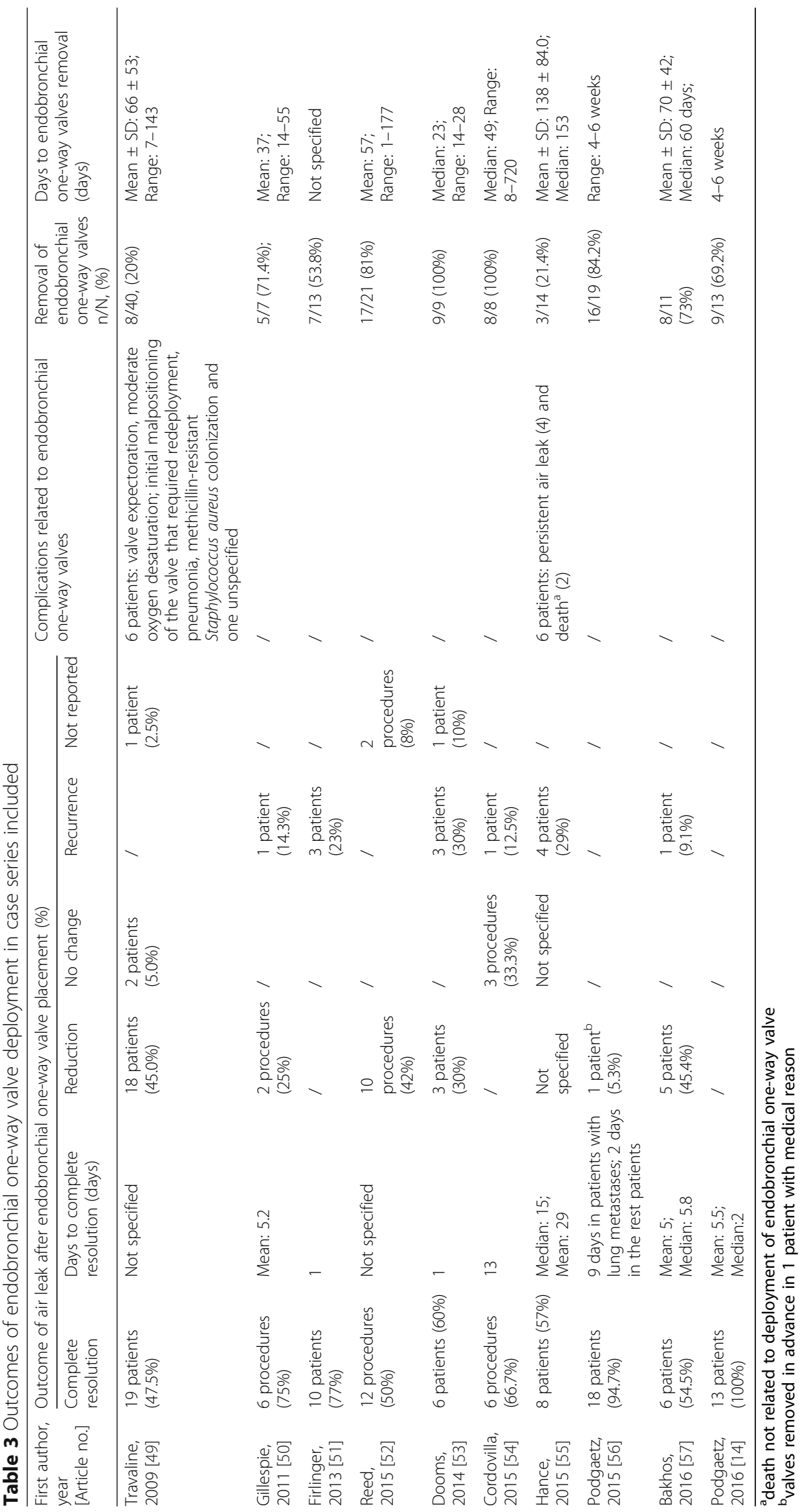


(57.7\%) patients received removal of endobronchial oneway valves and the mean duration of endobronchial oneway valve use was $23-138$ days. Recurrence was observed in 14/156 (9.0\%) patients. Travaline et al. reported 6 patients with complications related to endobronchial oneway valves in their case series in 2009: valve expectoration, moderate oxygen desaturation, initial malposition of the valve redeployment required, pneumonia, methicillinresistant Staphylococcus aureus colonization and one unspecified. Hance et al. reported 2 deaths after endobronchial one-way valve deployment but not related to the procedure. There was no other complication reported in the rest 148/156 (94.9\%) patients.

\section{Discussion}

The common treatment for PAL is surgery. However, for those patients with poor cardiopulmonary reserve, the risks of general anesthesia and surgical intervention pose a challenge [35]. Meanwhile, poor wound-healing characteristics could contribute to failure of surgery for PAL such as a low FEV1 percentage, and low maximum voluntary ventilation percentage, steroid use, prior radiochemotherapy, malnutrition, diabetes, etc. [51, 58]. Previous nonsurgical treatments for PAL have had limited success. Pleurodesis may indirectly impact air leak by creating pleural symphysis and localized inflammatory response, but data is lacking regarding its efficacy [59]. Likewise, autologous blood patch pleurodesis helps to seal air leak with the blood components that can initiate and support a fibrinous and inflammatory response, there is no substantive evidence that it results in earlier resolution of air leak [60].

There is a variety of bronchosopic management of air leak. The first description of bronchoscopic closure of PAL was reported by Hartmann and Rausch in 1977 using tissue glue [61]. Largest case series using glue sealant was reported by Hollaus et al. Forty-five male PAL patients were treated endoscopically for 13 years since
1983 using fibrin glue alone or combination with spongy calf bone depending on size of defects. Air leak was successfully sealed in 16/45 (36\%) patients and 2/16 (12\% failure rate) recurred [62]. Another category to eliminate air leaks endoscopically is sclerosants. Five patients with visible, central BPF were successfully treated by $100 \%$ ethanol injection without complication [63]. 23/35 (66\%) patients recovered completely after polidocanol injection without major complication [64]. Different from formers, thermal energy could also be used to treat air leaks. Aynaci et al. reported a successful elimination of air leak by using argon plasma coagulation (APC) which cauterized the area around two BPFs of 1 and $3 \mathrm{~mm}$ diameter [65].

A variety of devices employed other than licensed purposes consist of a large category of invasive broncoscopic technique in treating PALs, including Watanabe spigot, vascular occlusion coils, tracheobronchial stents, and Amplatzer occlude devices [66]. Sasada et al. reported a case series of 24 patients treated by Watanabe spigots. Complete resolution of air leak was observed in 12/24 (50\%) patients, and a reduction in 7/24 (29\%). 5/24 (21\%) patients showed no improvement. Complications were as following: migration of the spigot in 4/24(17\%) patients; fever, pneumonia, or lung abscess in 5/24 (21\%) [67].

Endobronchial one-way valves (Fig. 2) are one of the latest additions to the therapeutic armamentarium for PAL. Since that the interventions using flexible bronchoscopy is possible, it can be performed at the bedside in even the sickest patients [45]. A major benefit of bronchoscopic interventions lies in the fact that they are completely removable. Moreover, endobronchial one-way valves have its advantage for allowing expiration and clearance of distal bronchial secretions, therefore probably reducing the risk of post-obstructive pneumonia $[18,51]$.

The endobronchial one-way valve system comprises a delivery catheter, a loader system and the implantable valves. Endobronchial one-way valve delivery could

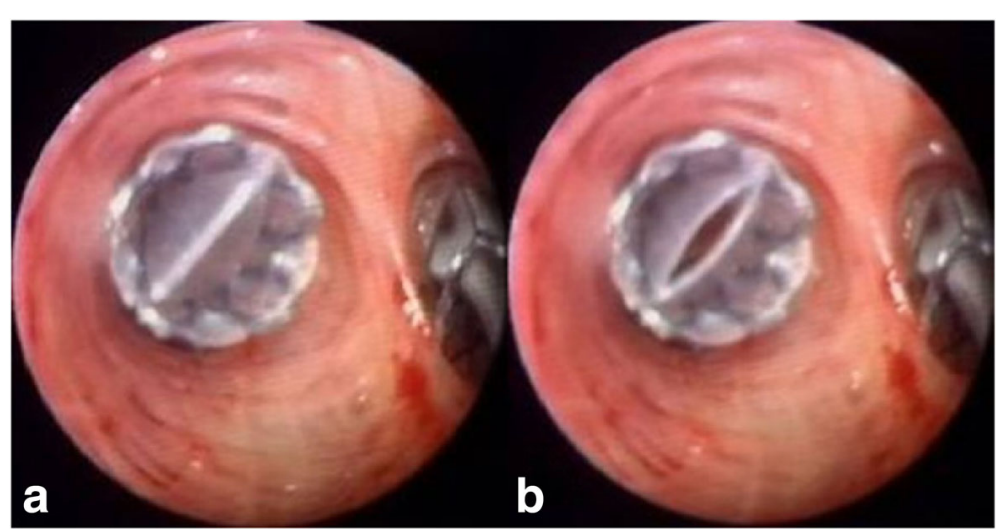

Fig. 2 Endoscopic view of one-way valve (a) inspiratory phase; (b) expiratory phase 
depend on either larger lumen of the rigid bronchoscopes or longer and thinner flexible bronchoscopes, the latter becomes the most common choice as it could be easily performed under moderate sedation and could help navigate into more distal bronchi [68]. Former endobronchial one-way valve, the Emphasys ${ }^{\oplus}$ (Emphasys Medical, Inc., Redwood City, CA) is no more commercially circulated. Endobronchial one-way valves are only approved for use in Europe under the name Zephyr ${ }^{\circ}$ made by Pulmonx while US FDA approved IBV under the name Spiration ${ }^{\circ}$ made by Olympus. The size of Spiration ${ }^{\circ}$ IBVs comes to $5 \mathrm{~mm}, 6 \mathrm{~mm}$, and $7 \mathrm{~mm}$, which is smaller than Zephyr ${ }^{\circ}$ valves with up to $8.5 \mathrm{~mm}$. It is not equal to compare the number of valves used in the procedure between Zephyr ${ }^{\circ}$ valves and Spiration ${ }^{\circ}$ IBV because it could be occurred that instead of using a larger valve to occlude the proximal bronchus, the smaller size would be chosen to be deployed at segmental bronchi to achieve complete occlusion [14].

Although methylene blue has been used for diagnosis of fistulas for many years, it is not frequently used in the treatment of PAL. Methylene blue could be seen within the bronchial tree leading to the fistula following being inserted via the chest tubes. The origin of the air leak could then be identified. Zeller et al. emphasized the use of methylene blue for guiding endobronchial one-way valve deployment. They reported identification of one bronchial segment leading to fistula by methylene blue inserting via chest tube which has not previously been identified by the common balloon method [38]. It could be suggested that it may be also helpful in identification of origin of the intermittent air leak which could not detected by balloon occlusion test.

Another helpful technique in the endobronchial oneway valve deployment procedure is the digital pleural drainage system which is able to continuously monitor and record the air leak in milliliter leakage per minute $\left(\mathrm{ml} / \mathrm{min}^{-1}\right)$ providing an objective and reproducible quantitative air leak assessment [32]. Pompili et al. conducted a multicenter international randomized study and showed that, compared with those managed with traditional devices, patients managed with digital drainage systems after lung resections experienced a shorter duration of chest tube placement, shorter hospital stays, and a higher satisfaction rate [69].

Chartis system is originally used to assess collateral ventilation between target lobe and adjacent lobes in endobronchial lung volume reduction. Interestingly, Tian et al. reported a successful treatment of PAL with Zephyr EBVs being placed in bronchus B1 after Chartis system assessment which indicated a significant and constant negative pressure following the catheter being inserted into the bronchus B1 and the balloon sealing the S1 segment [70].
It is believed that continuation of air leaks after valve deployment was due to collateral ventilation between the lobes [56]. Endobronchial lung volume reduction studies have showed underestimated existence of collateral ventilation, or even alveolar-alveolar anastomoses [71]. Absence of atelectasis after lobar exclusion for PAL on chest $\mathrm{x}$-ray is indicative of collateral ventilation which depends on the presence of incomplete fissures [32]. However, Rosell et al. reported a previous reduction of air debit in one patient treated with endobronchial one-way valves proceeding to complete resolution of PAL without further intervention. The simple reduction of the air debit may transform an incontrollable air leak into a situation for conservative management until it heals, and it should not be initially considered a failure [34].

Safety of endobronchial one-way valve implantation could be concluded according to complications listed from the available literature as valve migration or expectoration, moderate oxygen desaturation and infection of related lung. No death related to endobronchial one-way valve implantation has been found in our review. Since that decreased FEV1 after endobronchial one-way valve deployment is inevitable and even immediate respiratory failure has been reported, the patient should be carefully selected before treatment with endobronchial one-way valves in PAL [32, 53].

Endobronchial one-way valve implantation would produce a financial benefit as it can minimize direct hospital costs and eliminate the risks of potential complications. Podgaetz et al. reported that the average cost of the hospitalization before valve implantation was $\$ 14,605$ including all levels of care. Total cost of procedure, valves, and hospital stay since valve implantation was $\$ 13,900$ [14]. Dooms and his colleagues reported that in their study the median direct cost related to valve management was $€ 6970$ per patient [53]. Santini et al. reported that the mean cost of valve was $€ 4500$ whereas the average cost day per day in the intensive care unit in Italy was estimated to be $€ 1500$. Thus, a modest reduction in the intensive care unit would justify the use of endobronchial one-way valves as a cost-effective procedure [30].

Although endobronchial one-way valve implantation has now been performed in many countries, most of the studies have limitations of small number of patients included and lack of control. Prospective randomized control studies should be needed to evaluate the effects and safety of endobronchial one-way valve implantation.

\section{Conclusion}

PAL is a common clinical problem with significant morbidity and mortality. It's possible that traditional treatments are not feasible in high-risk patients and 
that air leak remains persistent in spite of traditional treatments. The use of endobronchial one-way valve adds to the armamentarium for non-invasive treatments of challenging PAL, especially those with difficulties of anesthesia, poor condition and high morbidity. With its minimal complications, endobronchial one-way valve is a considerable therapeutical option. Nevertheless, prospective randomized controlled trials with large sample should be needed to further evaluate the effects and safety of endobronchial one-way valve implantation in the treatment of PAL.

\section{Acknowledgements}

Not applicable.

\section{Funding}

There is no funding received.

\section{Availability of data and materials}

Not applicable.

\section{Authors' contributions}

The work presented here was carried out in collaboration between al authors. GY and YJ defined the research theme. ZX and GY designed database searching methods and data analysis; DM carried out the database searching, analyzed the data, interpreted the results and wrote the paper. All authors have contributed to, seen and approved the manuscript.

\section{Ethics approval and consent to participate}

Not applicable.

\section{Consent for publication}

Not applicable.

\section{Competing interests}

The authors declare that they have no competing interests.

\section{Publisher's Note}

Springer Nature remains neutral with regard to jurisdictional claims in published maps and institutional affiliations.

\section{Author details}

${ }^{1}$ Department of Respiratory Medicine, Zhongnan Hospital of Wuhan University, Donghu Road 169, Wuhan 430071, People's Republic of China. ${ }^{2}$ Center for Evidence-based and Translational Medicine, Zhongnan Hospital of Wuhan University, Donghu Road 169, Wuhan 430071, People's Republic of China.

Received: 3 June 2017 Accepted: 18 October 2017

Published online: 06 November 2017

\section{References}

1. Williams N, Lewis C. Bronchopleural fistula: a review of 86 cases. Br J Surg. 1976:63:520-2

2. Cerfolio RJ, Tummala RP, Holman WL, et al. A prospective algorithm for the management of air leaks after pulmonary resection. Ann Thorac Surg. 1998;66:1726-31

3. Brunelli A, Monteverdi M, Borri A, et al. Predictors of prolonged air leak after pulmonary lobectomy. Ann Thorac Surg. 2004;77:1205-10.

4. Lois M, Noppen M. Bronchopleural fistulas: an overview of the problem with special focus on endoscopic management. Chest. 2005;128:3955-65.

5. Mahajan AK, Doeing DC, Hogarth DK. Isolation of persistent air leaks and placement of intrabronchial valves. J Thorac Cardiovasc Surg. 2013;145(3): 626-30

6. Jones DR, Stiles BM, Denlinger CE, et al. Pulmonary segmentectomy: results and complications. Ann Thorac Surg. 2003;76:343-8.
7. Ciccone A, Meyers B, Guthrie T, et al. Long term outcome of bilateral lung volume reduction in 250 consecutive patients with emphysema. J Thorac Cardiovasc Surg. 2003;125:513-25.

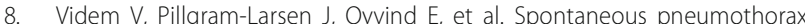
in COPD; complications, treatment and recurrences. Eur J Respir Dis. 1987:71:365-71.

9. Celik B. SahinE, NadirA, et al. iatrogenic pneumothorax: etiology, incidence and risk factors. Thorac Cardiovasc Surg. 2009;57(5):286-90.

10. Okereke I, Murthy SC, Alster JM, et al. Characterization and importance of air leak after lobectomy. Ann Thorac Surg. 2005;79(4):1167-73.

11. Okamoto J, Okamoto T, Fukuyama Y, et al. The use of a water seal to manage air leaks after a pulmonary lobectomy: a retrospective study. Ann Thorac Cardiovasc Surg. 2006 :12(4):242-4.

12. Alphonso $\mathrm{N}$, Tan $\mathrm{C}$, Utley $\mathrm{M}$, et al. A prospective randomized controlled trial of suction versus non-suction to the under-water seal drains following lung resection. Eur J Cardiothorac Surg. 2005 ;27(3):391-4

13. DeCamp MM, Blackstone EH, Naunheim KS, et al. Patient and surgical factors influencing air leak after lung volume reduction surgery: lessons learned from the National Emphysema Treatment Trial. Ann Thorac Surg. 2006;82:197-207.

14. Podgaetz E, Zamora F, Gibson H, et al. Intrabronchial valve treatment for prolonged air leak: can we justify the cost? Can Respir J. 2016;2867547:2016.

15. El-Sameed Y, Waness A, Al Shamsi I, et al. Endobronchial valves in the management of broncho-pleural and alveolo-pleural fistulae. Lung. 2012; 190(3):347-51.

16. Snell Gl, Holsworth L, Fowler S, et al. Occlusion of a broncho-cutaneous fistula with endobronchial one-way valves. Ann Thorac Surg. 2005:80(5):1930-2.

17. Toma TP, Kon OM, Oldfield W, et al. Reduction of persistent air leak with endoscopic valve implants. Thorax. 2007:62(9):830-3.

18. Feller-Kopman D, Bechara R, Garland R, et al. Use of a removable endobronchial valve for the treatment of bronchopleural fistula. Chest. 2006:130(1):273-5.

19. Ferguson JS, Sprenger K, Van Natta T. Closure of a bronchopleural fistula using bronchoscopic placement of an endobronchial valve designed for the treatment of emphysema. Chest. 2006;129(2):479-81.

20. Mitchell KM, Boley TM, Hazelrigg SR. Endobronchial valves for treatment of bronchopleural fistula. Ann Thorac Surg. 2006;81(3):1129-31.

21. De Giacomo T, Venuta F, Diso D, et al. Successful treatment with one-way endobronchial valve of large air-leakage complicating narrow-bore enteral feeding tube malposition. Eur J Cardiothorac Surg. 2006;30(5):811-2.

22. Anile M, Venuta F, De Giacomo T, et al. Treatment of persistent air leakage with endobronchial one-way valves. J Thorac Cardiovasc Surg. 2006;132(3):711-2

23. Fischer W, Feller-Kopman D, Shah A, et al. Endobronchial valve therapy for pneumothorax as a bridge to lung transplantation. J Heart Lung Transplant. 2012;31(3):334-6.

24. Mahajan AK, Verhoef $P$, Patel SB, et al. Intrabronchial valves: a case series describing a minimally invasive approach to bronchopleural fistulas in medical intensive care unit patients. J Bronchology Interv Pulmonol. 2012 19(2):137-41.

25. Abu-Hijleh M, Blundin M. Emergency use of an endobronchial one-way valve in the management of severe air leak and massive subcutaneous emphysema. Lung. 2010;188(3):253-7.

26. Schiavon M, Marulli G, Zuin A, et al. Endobronchial valve for secondary pneumothorax in a severe emphysema patient. Thorac Cardiovasc Surg. 2011;59(8):509-10.

27. Ambrosino N, Ribechini A, Allidi $F$, et al. Use of endobronchial valves in persistent air leaks: a case report and review of the literature. Expert Rey Respir Med. 2013;7(1):85-90.

28. Qi F, Tian $Q$, Chen $L$, et al. Use of endobronchial valve insertion to treat relapsing pneumothorax: a case report and literature review. Clin Respir J. 2015:10.

29. Conforti S, Torre M, Fieschi S, et al. Successful treatment of persistent postoperative air leaks following the placement of an endobronchial oneway valve. Monaldi Arch Chest Dis. 2010;73(2):88-91

30. Santini M, Fiorelli A, Vicidomini G, et al. latrogenic air leak successfully treated by bronchoscopic placement of unidirectional endobronchial valves. Ann Thorac Surg. 2010:89(6):2007-2010.

31. Schweigert $M$, Kraus D, Ficker $\mathrm{JH}$, et al. Closure of persisting air leaks in patients with severe pleural empyema-use of endoscopic one-way endobronchial valve. Eur J Cardiothorac Surg. 2011;39(3):401-3. 
32. Dooms CA, De Leyn PR, Yserbyt J, et al. Endobronchial valves for persistent postoperative pulmonary air leak: accurate monitoring and functional implications. Respiration. 2012;84(4):329-33.

33. WC Y, Yeung YC, Chang Y, et al. Use of endobronchial one-way valves reveals questions on etiology of spontaneous pneumothorax: report of three cases. J Cardiothorac Surg. 2009;4:63.

34. Rosell A, López-Lisbona R, Cubero N, et al. Endoscopic treatment of persistent alveolar-pleural air leaks with a unidirectional endobronchial valve. Arch Bronconeumol. 2011;47(7):371-3.

35. Alexander ES, Healey TT, Martin DW, et al. Use of endobronchial valves for the treatment of bronchopleural fistulas after thermal ablation of lung neoplasms. J Vasc Interv Radiol. 2012;23(9):1236-40.

36. Gudbjartsson T, Helgadottir S, Ek L. One-way endobronchial valve for bronchopleural fistula after necrotizing pneumonia. Asian Cardiovasc Thorac Ann. 2013:21(4):498-9.

37. Brichon PY, Poquet C, Arvieux C, et al. Successful treatment of a lifethreatening air leakage, complicating severe abdominal sepsis, with a one-way endobronchial valve. Interact Cardiovasc Thorac Surg. 2012;15(4):779-80.

38. van Zeller M, Bastos P, Fernandes $G$, et al. Clinical challenges of persistent pulmonary air-leaks-case report. Rev Port Pneumol. 2014;20(3):162-6.

39. Fielding DI, Bashirzadeh F, Deller D, et al. Life-saving closure of a pulmonary cavity by endobronchial valve placement. Am J Respir Crit Care Med. 2013;187(10):1145-6.

40. Jenkins M, Vaughan P, Place D, et al. Endobronchial valve migration. Eur J Cardiothorac Surg. 2011;40(5):1258-60.

41. Seyfried U, Firlinger I, Reiter M, et al. A leak in the lung: endobronchial oneway valve placement as treatment for a persistent bronchopleural fistula. Pneumologie. 2012;66(3):188-91.

42. Venkatappa N, Fadul R, Raymond D, et al. Endobronchial valves for treatment of bronchopleural fistula in granulomatous polyangitis: a longitudinal case report. J Bronchology Interv Pulmonol. 2013;20(2):186-8.

43. Tsim S, Paton L, Nicholson F, et al. Rescue therapy using an endobronchia valve and digital air leak monitoring in invasive pulmonary aspergillosis. Respir Med Case Rep. 2014;14:27-9.

44. Morrison M, Marshall A, Giavedonni S, et al. Case report: endobronchial valve placement for treatment of a persistent air leak. Breathe (Sheff). 2016;12(1):61-4.

45. Hodges AM, Gillham MJ, Lewis CA. Bedside placement of an endobronchial valve to aid invasive ventilation and weaning from extracorporeal membrane oxygenation. Crit Care Resusc. 2015;17(3):219-22.

46. Kalatoudis $\mathrm{H}$, Nikhil M, Zeid F, et al. Bronchopleural fistula resolution with endobronchial valve placement and liberation from mechanical ventilation in acute respiratory distress syndrome: a case series. Case Rep Crit Care. 2017:3092457:2017.

47. Ballay N, Soder B, Smith J, et al. Intrabronchial pneumonectomy for vanishing lung syndrome: first reported case. Ann Thorac Surg. 2017; 103(3):e277-9.

48. Spratt JR, Podgaetz E, Loor G, et al. Endobronchial valve therapy for a refractory air leak after lung transplantation in a patient with multiple connective tissue disorders. J Thorac Cardiovasc Surg. 2017;153(1):e17-8.

49. Travaline JM, McKenna RJ Jr, De Giacomo T, et al. Treatment of persistent pulmonary air leaks using endobronchial valves. Chest 2009; 136(2):355-360

50. Gillespie CT, Sterman DH, Cerfolio RJ, et al. Endobronchial valve treatment for prolonged air leaks of the lung: a case series. Ann Thorac Surg. 2011; 91(1):270-3

51. Firlinger I, Stubenberger E, Müller MR, et al. Endoscopic one-way valve implantation in patients with prolonged air leak and the use of digital air leak monitoring. Ann Thorac Surg. 2013;95(4):1243-9.

52. Reed MF, Gilbert CR, Taylor MD, et al. Endobronchial valves for challenging air leaks. Ann Thorac Surg. 2015;100(4):1181-6.

53. Dooms CA, Decaluwe $H$, Yserbyt J, et al. Bronchial valve treatment for pulmonary air leak after anatomical lung resection for cancer. Eur Respir J. 2014:43(4):1142-8.

54. Cordovilla R, Torracchi AM, Novoa N, et al. Endobronchial valves in the treatment of persistent air leak, an alternative to surgery. Arch Bronconeumol. 2015;51(1):10-5.

55. Hance JM, Martin JT, Mullett TW. Endobronchial valves in the treatment of persistent air leaks. Ann Thorac Surg. 2015;100(5):1780-5.
56. Podgaetz E, Andrade RS, Zamora F, et al. Endobronchial treatment of bronchopleural fistulas by using Intrabronchial valve system: a case series. Semin Thorac Cardiovasc Surg. 2015 Summer;27(2):218-22.

57. Bakhos C, Doelken P, Pupovac S, et al. Management of Prolonged Pulmonary Air Leaks With Endobronchial Valve Placement. JSLS. 2016;20(3)

58. Cerfolio RJ, Bass CS, Pask AH, et al. Predictors and treatment of persistent air leaks. Ann Thorac Surg. 2002;73:1727-31.

59. Wood DE, Cerfolio RJ, Gonzalez X, et al. Bronchoscopic management of prolonged air leak. Clin Chest Med. 2010;31(1):127-33.

60. Oliveira FH, Cataneo DC, Ruiz RL Jr, et al. Persistent pleuropulmonary air leak treated with autologous blood: results from a university hospital and review of literature. Respiration 2010; 79(4):302-306

61. Hartmann W, Rausch V. New therapeutic application of the fiberoptic bronchoscope. Chest. 1977;71(2):237.

62. Hollaus PH, Lax F, Janakiev D, et al. Endoscopic treatment of postoperative bronchopleural fistula: experience with 45 cases. Ann Thorac Surg. 1998; 66(3):923-7.

63. Takaoka K, Inoue S, Ohira S. Central bronchopleural fistulas closed by bronchoscopic injection of absolute ethanol. Chest. 2002;122(1):374-8.

64. Varoli F, Roviaro G, Grignani F, et al. Endoscopic treatment of bronchopleural fistulas. Ann Thorac Surg. 1998;65(3):807-9.

65. Aynaci $\mathrm{E}$, Kocatürk $\mathrm{Cl}$, Yildiz $\mathrm{P}$, et al. Argon plasma coagulation as an alternative treatment for bronchopleural fistulas developed after sleeve pneumonectomy. Interact Cardiovasc Thorac Surg. 2012;14(6):912-4.

66. Slade M. Management of pneumothorax and prolonged air leak. Semin Respir Crit Care Med. 2014:35(6):706-14.

67. Sasada S, Tamura K, Chang YS, et al. Clinical evaluation of endoscopic bronchial occlusion with silicone spigots for the management of persistent pulmonary air leaks. Intern Med. 2011;50(11):1169-73.

68. Gkegkes ID, Mourtarakos S, Gakidis I. Endobronchial valves in treatment of persistent air leaks: a systematic review of clinical evidence. Med Sci Monit. 2015;21:432-8.

69. Pompili C, Detterbeck F, Papagiannopoulos K, et al. Multicenter international randomized comparison of objective and subjective outcomes between electronic and traditional chest drainage systems. Ann Thorac Surg. 2014;98:490-7.

70. Tian Q, Qi F, An Y, et al. Using the Chartis system to selectively target a lung segment with a persistent air leak. Eur Respir J. 2013;41(6):1461-3.

71. Fessler HE. Collateral ventilation, the bane of bronchoscopic volume reduction. Am J Respir Crit Care Med. 2005;171:423-4.

\section{Submit your next manuscript to BioMed Central and we will help you at every step:}

- We accept pre-submission inquiries

- Our selector tool helps you to find the most relevant journal

- We provide round the clock customer support

- Convenient online submission

- Thorough peer review

- Inclusion in PubMed and all major indexing services

- Maximum visibility for your research

Submit your manuscript at www.biomedcentral.com/submit 